\title{
La evolución de las escuelas de arquitectura
}

Josep Quetglas (Palma de Mallorca, 1946) es arquitecto por la Escuela Técnica Superior de Arquitectura de Barcelona y, desde 1980, catedrático de la Universitat Politècnica de Catalunya. Es autor de los siguientes títulos: Escritos colegiales: La casa de Don Giovanni; El horror vitrificado: imágenes del PabeIlón de Alemania; Pasado a limpio I y II; Artículos de ocasión y, recientemente, Les Heures Claires. Desde 2002 dirige el anuario Massilia. Annuaire d'études corbuséennes. Ha recibido numerosos premios y reconocimientos, como el por la Generalitat de Carquitectura
El mercado desvía el derecho a la propiedad colectiva de los conocimientos, y los intenta aspirar en provecho de algunos grupos a parconcretos. Transmisión de conocimientos $y$ mercado son hostiles, y la enseñanza de la arquitectura sobre la tierra se produce en este

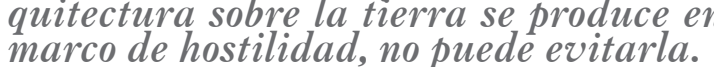

El texto que sigue a continuación recoge extractos de la ponencia que, con motivo de las Jornadas Barcelona-Madrid organizadas por la Cátedra, Blanca y realizadas en el Col. legi Oficial d'Arquitectes de Catalunya en mayo de 2005, Josep Quetglas pronunció en el marco del debate sobre la enseñanza de la ar. quitectura.

"Tengo 42 años y no soy más que un estudiante de arquitectura".

Obviamente no soy yo quien lo dice. Lo dice Le Corbusier en 1930, en el primer tomo de sus obras completas. Yo soy más viejo y peor estudiante de arquitectura que individuo interesado en la arquitectura que hago un par de comentarios.

El primer comentario es sobre el motivo de estas sesiones dentro de las jornadas Barcelona-Madrid, Arquitecturas, organizadas por la Cátedra Blanca con la colaboración del COAC, que respetuosa pero a la vez distante, para postular que el centro de gravedad de la arquitectura española sigue oscilando entre Madrid y Barcelona.

Pero, ¿cuándo este centro de gravedad ha estado en Madrid y Barcelona? ¿Cuál es la zona donde más riqueza hay en arquitectura, por ejemplo racionalista, de

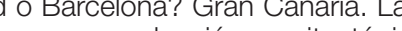
ca que no fue igualada en aquel tiempo y no es mantenida ahora por ninguna de estas, no sé por qué, autoproclamadas capitales de la arquitectura. ¿Dónde se construye el primer edificio racionalista? ¿En Madrid o en Barcelona? En Zaragoza. ¿Cuál es el nalista? ¿En Madrid o en Barcelona? En Zaragoza. ¿Cuál es el lápiz? ¿Es uno de Madrid o es uno de Barcelona? Es un donostiarra. ¿Cómo se puede afirmar que la historia del último siglo de arquitectura en España se focaliza en ese doble polo de Madrid y Barcelona? ¿Aníbal González no ha marcado Sevilla de una
forma tan intensa como sus contemporáneos en Madrid o Barcelona? ¿En Galicia no ha habido nadie? ¿Quién hay a la altura de un Bar Boo en la arquitectura de Madrid o Barcelona en los años 50? ¿Quién ha comprendido tan bien a Wright como ese gallego? A mí me parece que el punto inicial de la convocatoria está cojo. Da una versión tremendamente escasa de lo que ha la arquitectura de los últimos 100 o 150 años por estas tierras. Parto, por lo tanto, de una desconfianza hacia el hecho de que tengamos que estar endogámicamente en esa doble capitalidad producido en numero y en ejemplos fuera de esos dos ámbitos.

Pero lo qué quizá nos atrae de esa pareja es que "Madrid y están desde siempre confrontadas". Pues yo tampoco me he enterado de esto. Si hablásemos de España y Cataluña de la población que ven una un sentimiento difundido entre capas o de pertenencia nacional. Pero entre Madrid y Barcelona esto - durrió quizá sólo, u Madrid que sôlo, un sollo subrayado

Parto, por lo tanto, de una desconfianza hacia el hecho de que tengamos que estar enMadrid o Barcelona. No es cierto. La mejor arquitectura se ha producido en número y en ejemplos fuera de esos dos ámbitos.

Han sido dos ciudades donde no veo que sea posible, más que en las páginas de deportes, alimentar tensiones o enfrentamientos, especialmente si uno habla de arquitectos y arquitectura, porque ¿a qué calle hay que ir a ver el mejor edificio edificio Girasol. ¿Y la mejor arquitectura madrileña? Pues es el Ensanche de Cerdá, un proyecto que nos llega desde la Reina Castiza, hecho de la mano de una autoridad, militar, por su-
puesto. Naturalmente que estamos acostumbrados a pensar puesto. Naturalmente que estamos acostumbrados a pensa
En otro punto, la tercera pata que apoya esta convocatoria, entender, es algo parecido a la primera frase que ha dicho Paricio: "estamos discutiendo de galgos o podencos". Estamos discutiendo de Madrid y Barcelona cuando es esa turba de arquitectos internacionales cosmopolitas que sobrevuela el mundo y que baja en picado para picar en cualquier gran oportunidad de proyecto. Tampoco estoy de acuerdo con esto. La arquitectura es de un lugar, los arquitectos, no. Ayer estuvimos viendo los proyectos de Pepe Llinás y de Carlos Ferrater, donde palpar e suelo, tanto geográfica como memorísticamente, era el material con el que el proyecto se fabricaba. Obviamente una biblioteca Coruña. Pero que la arquitectura no pueda evitar estar arraigada, no pueda evitar ser de un emplazamiento, de unas coordenadas geográficas, históricas, sentimentales muy precisas, eso el suelo. El mejor arquitecto ibicenco ha construido en Toledo, en Castelldefels y en Japón. Y el mejor arquitecto mallorquín, en Mallorca, en Girona y en Nápoles. Cinco o seis siglos separan a Elías Torres de Guillermo Sagrera. Siempre los arquitectos han independiente respecto al gremio local, capacitado por su conocimiento profesional para trabajar en Lieja, en Hamburgo, en Lyon o en Salamanca.

Que la arquitectura no pueda evitar estar arraigada, no pueda evitar ser de un emplazamiento, de unas coordenadas geográficas, históricas, sentimentales muy precisas, eso no implica que el arquitecto también sea un árbol arraigado en el suelo.

Dicho esto paso a hacer algún comentario sobre la sesión que corresponde hoy que es la enseñanza de la arquitectura,

¿Qué es eso de la enseñanza de la arquitectura? Desde mi punto de vista, preguntarse por cómo se enseña arquitectura o cuáles los problemas o las tendencias que tiene la enseñanza de la arquitectura, equivale a preguntar, ¿a qué temperatura hierve el agua? Yo que sé. O me localiza dónde está proponiendo enseñar arquitectura, o no tengo nada que decir sobre esta pregunta tan global y vacía. Por ello, he supuesto que tenemos que montar el campamento para enseñar arquitectura no sé dónde está pero se me ocurre que, para cubrir todas las posibilidades, sólo se puede enseñar arquitectura en el Cielo, en la Tierra y en el Infierno.

Empiezo por el Cielo. Para mí enseñar arquitectura en e Cielo es hacer lo que Frank Lloyd Wright, Adolf Loos o Le Corbusier cuentan. Cuando leo las páginas donde esta gente explica cómo se aprende me parece estar en una situación de beatitud de niño, cuando su tío granjero, decidido y voluntarioso, le va a enseñar a andar. La conclusión de esta página es que uno puede enseñar pero quien aprende, aprende cosas que no están previstas por quien le enseña. $Y$ esto lo hace porque se apodera de ellas, porque en algún momento infringe el programa de lección que el tio del pequeño Frankie tenía aprendido. Esta primera página ilustrada con un dibujo, para mí es el modelo que cualtura, debe seguir porque ocurre esta relación de aprender y enseñar en una combinación muy asimétrica. Quien enseña tiene muy claro lo que quiere enseñar, pero no es eso lo que enseña puesto que quien aprende toma cosas que no están previstas y quien le está enseñando. Para mí, en el paraíso, estos son los profesores, y el método es el que a su lado uno aprendería.

Pero estamos en la Tierra, y aquí el aprendizaje no consiste en la invención de conocimientos sino en la transmisión de los mismos. Esta sabiduría es de propiedad y producción colectiva, ye transfiere de unas generaciones a otras. Si eso se corta o se deforma, es la propiedad colectiva la que esta perdiendo uno mundo terrestre, esta cadena de relevos viene distorsionada por un sistema magnético que modifica todo nuestro comportamiento, que es el mercado. El mercado desvía el derecho a la en provecho de algunos grupos a partir de la obtención de beneficios económicos concretos. Transmisión de conocimientos tierra se produce hostiles, y la enseñanza de la arquitectura sobre la La existencia, por ejemplo, de escuelas privadas es un signo de ello. Pero volviendo al foco de la discusión, para mí, una escuela pública de arquitectura tendría que explicar dos cosas: la profesión como ya no se hace, y la profesión como todavía no se hace. con otros campos de oficio. Por ejemplo, a alguien que estudia cocina le van a enseñar a hacer salsas como se hacían en los restaurantes de París del siglo XIX, pero también le enseñarán a hacerlas como todavía no se hacen en los restaurantes de Tokio del siglo XXI. Lo que no van a enseñarle es como se hacen ahora las salsas, porque para esto uno se va a una cocina a trabajar y lo aprende. Uno se adiestra en esto. Yo creo que esto es lo que distingue una escuela de arquitectura interesada en la formación de arquitectos, es decir, en la transmisión de los conocimientos de un tiempo a un tiempo que está por llegar. Es un centro de es doblemente anacrónica, hacia atrás y hacia adelante.

en el Infierno? Si el Paraíso sólo lo conozco, quizá cuando sueño, y si la Tierra la conozco mirando a mi alrededor, para conocer el Infierno creo que uno puede desplazarse hasta la EtsaB, y ahí tiene la imagen de la enseñanza de la arquitectura en el Infierno. Digo la EtsaB porque es lo que tengo más próximo, pero estoy convencido que cualquier persona de Valencia, de Madrid de La Coruña, nombraría inmediatamente su infierno particular, y no coincidirían con el mío en el nombre aunque posiblemente sí en el sistema de comportamiento. Las legiones al servicio de Satanás son numerosísimas. ¿En qué dad y la EtsaB están abiertas a la sociedad. Son esponjas, no son envoltorios impermeables y cerrados, sino que reciben las influencias de la sociedad y por lo tanto reproducen y asimilan en su interior las formas políticas y sociales que corresponden a nuestro tiempo. ¿Cuáles son las formas políticas y sociales de nuestro tiempo? Permitidme que a las primeras les llame "Franquismo constitucional" y a las segundas "Mafiocracia", entiendo por mafia aquellos vínculos de servicio y obediencia a cambio de protección y favores. Esta malla tan estrecha de relaciones se insufla también en un
pueda ser la EtsaB.

Jaume Sanmartí ha hecho una propuesta muy clara, y ya ha advertido que la suya sería una ponencia abierta a la protan el extrema a la discusión como a la indignación. Yo estaría en la academia es víctima del gremio, entiendo que academia es la escuela y gremio es la profesión. Para mí, por el contrario, una de las partes mas valiosas que ha caracterizado durante entretejido entre la profesion y la escuela. En sus aulas uno encontraba dando claen Barcelona. No había despachos por un lado y endogámicos académicos por el otro.

Existen dos tipos de personas dando clase. Los que en su vida profesional no obtienen satisfacciones y deben refugiarse en la escuela. Y aquellos que puesto que en su vida profesional obtienen satisfacciones, y creen que éstas no vienen de lo que ellos mismos han inventado sino que de lo que han aprendido, se sienten en la obligacion de enseñarlo a los otros.

Por desgracia esta situación ya no existe, cosa que consicio una de las mayores, no debilidades, sino autenticas aberraque controlan la escuela y los arquitectos de los cuales aprendemos por sus proyectos. No voy a alargarme leyendo la lista del quince o dieciséis nombres y os preguntaría: de estos nombres, ¿de cuántos conocéis un proyecto? Vaticino la respuesta. En mi caso concreto, de dos de ellos. El resto son profesionales, en términos despectivos, de la academia, profesionales de colocarse en los lugares de rentabilidad académica. Existen dos tipos de personas dando clase. Los que en su vida profesiona no obtienen satisfacciones y deben refugiarse en la escuela. $Y$ aquellos que puesto que en su vida profesional obtienen satisfacciones, y creen que éstas no vienen de lo que ellos mismos la obligación de enseñarlo a los otros. Aquellos que están en la EtsaB porque les gusta cómo trabajan y se sienten responsables de enseñar arquitectura, pueden encontrarse, como aque ser labriego, después de buscarlos con una lámpara entre los grupos bien aposentados. 